\title{
Another innovation in surgery for primary spontaneous pneumothorax (for men only)
}

\author{
Michael K. Hsin, MD, FRCS CTh
}

From the Department of Cardiothoracic Surgery, Queen Mary Hospital, Hong Kong.

Disclosures: Author has nothing to disclose with regard to commercial support.

Received for publication July 7, 2016; accepted for publication July 11, 2016; available ahead of print Aug 16, 2016

Address for reprints: Michael K. Hsin, MD, FRCS CTh, Department of Cardiothoracic Surgery, Queen Mary Hospital, Room 308, 3/F New Clinical Building, 102 Pok Fu Lam Rd, Hong Kong (E-mail: mkhsin@ hotmail.com). J Thorac Cardiovasc Surg 2016;152:1006-7

$0022-5223 / \$ 36.00$

Copyright $(9) 2016$ by The American Association for Thoracic Surgery

http://dx.doi.org/10.1016/j.jtcvs.2016.07.042

The surgical approach for primary spontaneous pneumothorax (PSP) has evolved from thoracotomy to 3-port video-assisted thoracoscopic surgery (VATS), which has become the favored option. More recently, 2-port and uniport approaches for PSP are gaining interest. ${ }^{1-3}$

In this issue of the Journal, Lin and colleagues ${ }^{4}$ report yet another innovation in the surgical treatment of PSP with bullectomy and pleural abrasion using a transareolar incision. At the time of writing, there were 3 other published cardiothoracic surgery papers describing the use of transareolar approach in sympathectomy, ${ }^{5}$ robotic mitral valve surgery, ${ }^{6}$ and lung wedge resection.

In the current series, 112 male patients with PSP underwent transareolar bullectomy, which is essentially a 2-port access through the third and fourth intercostal spaces, with the incisions made over the superior and inferior aspects of the areola. Blebs were resected with endostapling, and mechanical pleural abrasion was performed. Because the majority of blebs occurred in the apical segment of the upper lobe, this access provided a direct path to the target area. The transareolar approach is not suitable for female patients, for fear of damaging the mammary glands, and obese patients, because of the variable position of the areola. The authors concluded that the transareolar approach resulted in excellent cosmetic results and patient satisfaction at with no recurrence at 1-year follow-up.

One important piece of information that the authors did not provide in the manuscript is the percentage of patients who had a previous PSP and the percentage of first-time PSP. The authors stated that all patients underwent preoperative computed tomography (CT), and, if blebs were detected, then surgery would be offered even in patients with first-time PSP. This management algorithm is at variance with the recommendations from published guidelines on the management of PSP. The guideline from the American College of Chest Physicians does not recommend surgery for first-time pneumothorax, unless there is persistent airleak. ${ }^{8}$ The guideline of the British Thoracic Society recommends surgery for first-time PSP

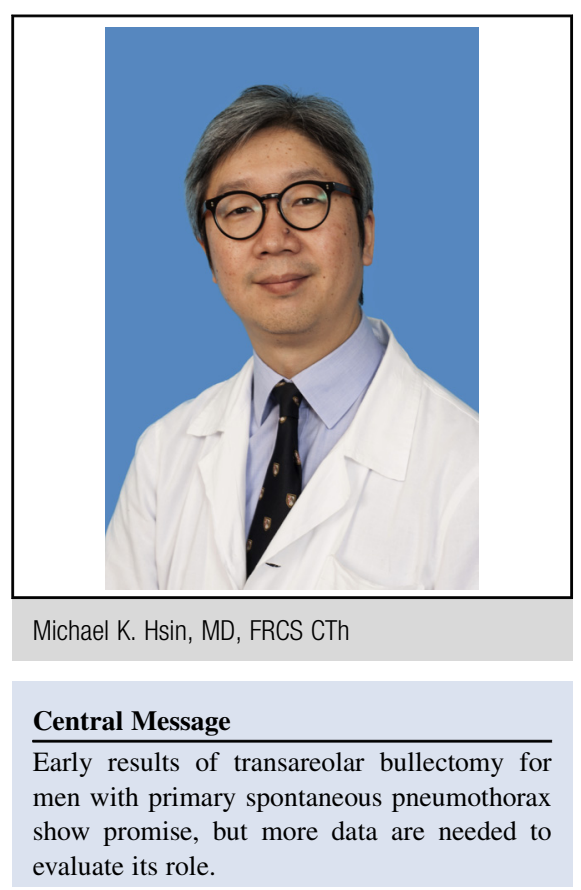

See Article page 999.

in the following situations: first-time contralateral, persistent airleak, failure of re-expansion, synchronous bilateral, or at risk professions. ${ }^{9}$ Admittedly, some authors suggest surgery may be offered in first-time PSP, but this is not the prevalent practice. ${ }^{10}$

The routine use of CT is not recommended by either the American College of Chest Physicians or the British Thoracic Society, ${ }^{8,9}$ although this is more because of practical constraints. Because the transareolar approach may be unsuitable where there are multiple complex bullae, a preoperative CT would be useful for patient selection.

Lin and colleagues ${ }^{4}$ stated that VATS bullectomy/ pleurodesis via a 2-port or uniport technique requires expensive devices and incurs poor maneuverability when conventional instruments are used. Proponents of uniport VATS may disagree with this statement, although few would argue against the excellent cosmetic results with the transareolar bullectomy over the more "conventional" multiport or uniport approach.

Transareolar bullectomy is a promising innovation, and the authors should report long-term data, particularly in patients with recurrent pneumothorax, to help determine its place in the management of PSP. 


\section{References}

1. Salati M, Brunelli A, Xiumè F, Refai M, Sciarra V, Soccetti A, et al. Uniportal video-assisted thoracic surgery for primary spontaneous pneumothorax: clinical and economic analysis in comparison to the traditional approach. Interact Cardiovasc Thorac Surg. 2008;7:63-6.

2. Yamazaki K, Haratake N, Shikada Y, Mori R, Kouso H, Shoji F, et al. Initial experience of single-incision thoracoscopic surgery for 100 patients with primary spontaneous pneumothorax. Ann Thorac Cardiovasc Surg. 2015;21:513-6.

3. Foroulis CN, Anastasiadis K, Charokopos N, Antonitsis P, Halvatzoulis HV, Karapanagiotidis GT, et al. A modified two-port thoracoscopic technique versus axillary minithoracotomy for the treatment of recurrent spontaneous pneumothorax: a prospective randomized study. Surg Endosc. 2012;26:607-14.

4. Lin JB, Chen JF, Lai FC, Li X, Qiu ML. Transareolar pulmonary bullectomy for primary spontaneous pneumothorax. J Thoracic Cardiovasc Surg. 2016;152: 999-1005.

5. Chen J, Lin J, Tu Y, Lin M, Li X, Lai F. Nonintubated transareolar endoscopic thoracic sympathectomy with a flexible endoscope: experience of 58 cases. Ann Thorac Cardiovasc Surg. 2016;22:12-9.

6. Musumeci F, Mariscalco G, Ranocchi F, Tosi D, Persichetti P. Transareolar robotic-assisted access to the mitral valve. Innovations (Phila). 2015;10 438-40.

7. Xu K, Bian W, Xie H, Ma H, Ni B. Single-port video-assisted thoracoscopic wedge resection: novel approaches in different genders. Interact Cardiovasc Thorac Surg. 2016;23:202-7.

8. Baumann MH, Strange C, Heffner JE, Light R, Kirby TJ, Klein J, et al. AACP AACP Pneumothorax Consensus Group. Management of spontaneous pneumothorax: an American College of Chest Physicians Delphi consensus statement. Chest. 2001;119:590-602.

9. MacDuff A, Arnold A, Harvey J. BTS Pleural Disease Guideline Group. Management of spontaneous pneumothorax: British Thoracic Society Pleural Disease Guideline 2010. Thorax. 2010;65(suppl 2):ii18-31.

10. Chambers A, Scarci M. In patients with first-episode primary spontaneous pneumothorax is video-assisted thoracoscopic surgery superior to tube thoracostomy alone in terms of time to resolution of pneumothorax and incidence of recurrence? Interact Cardiovasc Thorac Surg. 2009;9: 1003-8. 